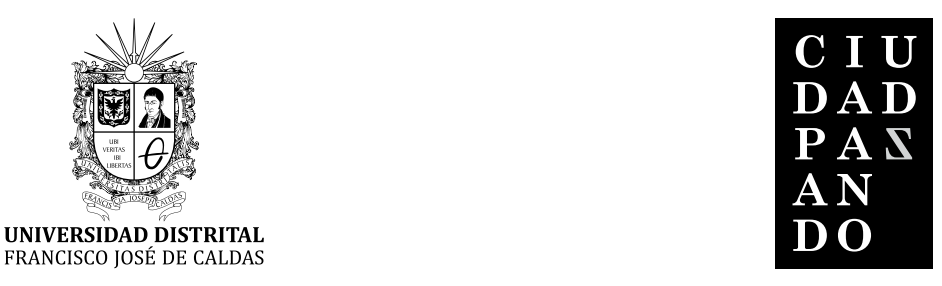

DOSSIER

Artículo de investigación científica

\title{
El teatro, una alternativa pedagógica para fomentar la cultura de paz en la IERD Andes*
}

The theater, an educational alternative to promote a culture of peace in the IERD Andes

O teatro, uma alternativa pedagógica para fomentar a cultura de paz na IERD Andes

\section{Patricia Posso R., ${ }^{1}$ Matilde Inés Mejía, ${ }^{2}$ Oscar Andrés Prado E., ${ }^{3}$ y Luis Giovanni Quiceno ${ }^{4}$}

Para citar este artículo: Posso, P., Mejía, M., Prado, O. y

Quiceno, L. (2017). El teatro, una alternativa pedagógica para

fomentar la cultura de paz en la IERD Andes. Revista Ciudad

Paz-ando, 10.1, 68-81

doi: https://doi.org/10.14483/2422278X.11695

Fecha de recepción: 3 de marzo de 2017

Fecha de aceptación: 20 de junio de 2017

\footnotetext{
* Resultado de la investigación "El teatro, una alternativa pedagógica para fomentar una cultura de paz en las aulas”. La sigla IERD equivale a Institución Educativa Rural Departamental.

1 Docente investigadora, Universidad Cooperativa de Colombia. Correo electrónico: patricia.posso@campusucc.edu.co

2 Directora de Desarrollo Social, Fundación PAIS XXI (PAIS21). Correo electrónico: matilde.mejia@fundacionpais21.org

3 Docente Español, Institución Educativa Rural Departamental Andes. Correo electrónico: kitaros7@hotmail.com

4 Docente Lengua castellana, Colegio Campestre Jaime Garzón. Correo electrónico: licenciadogiovanni@hotmail.com.
} 


\section{RESUMEN}

El artículo presenta los resultados de investigación sobre de la incidencia de la práctica del teatro al interior de la escuela, para fomentar la cultura de paz en los estudiantes de grado noveno de la Institución Educativa Rural Departamental Andes, un colegio del Municipio de San Bernardo Cundinamarca; a partir de argumentos teóricos y conceptuales, así como el resultado de una propuesta pedagógica aplicada, centrada en el teatro. La metodología utilizada fue investigación-acción pedagógica, mediante la cual se comprobó que el teatro sirve como un instrumento didáctico para mejorar las relaciones de convivencia y el fortalecimiento de valores esenciales para lograr una cultura de paz.

Palabras clave: alternativa pedagógica, cultura de paz, teatro.

\section{ABSTRACT}

This article presents an investigation results about the incidence that the practice of the theater can have inside the school in order to foment the peace culture in ninth grade students of Institución Educativa Rural Departamental Andes, a San Bernardo's school in Cundinamarca; based on theoretical and conceptual arguments and the result of an applied pedagogical proposal, based on the theater. Methodology used was Investigación acción pedagógica, which proved that the theater can be used as a didactic instrument to improve the coexistence relations, and strength the main values to achieve a peace culture.

Keywords: culture of peace, pedagogical alternative, theater.
$\mathrm{O}$ artigo apresenta os resultados da pesquisa sobre a incidência da prática teatral dentro da escola, para promover uma cultura de paz nos alunos da nona série da Institución Educativa Rural Departamental Andes, uma escola no município de San Bernardo - Cundinamarca; de argumentos teóricos e conceituais e o resultado de uma abordagem pedagógica aplicada, centrada no teatro. A metodologia utilizada foi Investigación acción pedagógica pelo qual verificou-se que o teatro serve como uma ferramenta de ensino para melhorar as relações de convivência e valores fundamentais de fortalecimento para alcançar uma cultura de paz.

Palavras-chave: alternativa educacional, cultura de paz, teatro 


\section{Introducción}

El teatro, una alternativa pedagógica para fomentar la cultura de paz en las aulas, es una apuesta de reflexión alrededor del ejercicio docente, el cual parte de la necesidad de generar consciencia sobre lo que las instituciones educativas pueden hacer a favor de la paz. En este sentido, se plantea que el arte dramático puede generar acciones positivas y sentimientos colaborativos tanto a favor del ser humano como del ambiente que le rodea; por este motivo, el teatro se presenta como una opción de aprendizaje capaz de contrarrestar la pérdida de valores, la indiferencia y la violencia en general que hoy asiste en el interior de las escuelas.

La pregunta que se responderá en este artículo es ¿qué incidencia tiene la práctica del teatro al interior de la escuela para fomentar la cultura de paz? Este interrogante llevará a cruzar diversas posiciones a través de autores como Fisas, Tuvilla, Corredor, Assaél, J., Scherping, G., y Pavez, J. Boal, Cacopardo, Cañas, Corredor, Vigotsky, Cutillas y Gual,entre otros, quienes desde sus más altas certezas comprobarán dicha tesis.

Así pues, el teatro no es solo un medio de entretenimiento, como quizá se ha considerado, es una estrategia y alternativa pedagógica que puede ser usada en las aulas de una manera más formal, positiva y planeada; de cierta forma, controlada, para obtener resultados donde quizá otras estrategias o alternativas han fracasado.

Como se ha dicho, uno de los temas donde se tiene más problema dentro de las escuelas es la convivencia, pues cada vez se refleja más la pérdida de valores y a su vez la falta de alternativas eficaces para la solución pacífica de conflictos; la educación tradicional no ha dado muchas estrategias para mejorar este flagelo, en la escuela se atacan las consecuencias pero no las causas, se hace una anotación en el observador, se cita al acudiente, y en caso extremo se produce la expulsión del estudiante. Por lo tanto, se hacen necesarias estrategias activas, centradas en el interés del estudiante, que intervenga en las causas y ponga al estudiante en el protagonismo de su proceso de formación permitiendo que la cultura de paz se construya paso a paso sin descuidar el aspecto académico. Esta estrategia es el teatro en la escuela, alternativa pedagógica mediante la cual se podría mejorar la convivencia y la cultura de paz en las instituciones educativas.

De tal manera, el objetivo de este artículo es evidenciar la relación que existe entre el teatro con la cultura de paz, exponer las competencias que se pueden fortalecer a través de él y su relevancia académica como alternativa pedagógica lúdica y didáctica. Finalmente, se compartirán los resultados del proyecto "El teatro en la escuela, una alternativa pedagógica para fomentar la cultura de paz en la Institución Educativa Rural Andes de San Bernardo Cundinamarca", el cual se ha desarrollado e implementado en dicha institución mediante el paradigma investigación-acción pedagógica, en una población netamente rural y con una muestra de diecinueve estudiantes de grado noveno.

\section{Fundamentación teórica}

En el mundo helénico, los dramaturgos griegos fueron, junto con Homero, los principales educadores del pueblo, ya que eran la base de la formación cultural del ciudadano (Gual 2005); así, tanto la comedia como las tragedias griegas, fueron fundamentales, no solo para enseñar de qué estaba hecho el mundo, sino para sensibilizar al pueblo sobre aspectos como la guerra. En Lisístrata, por ejemplo, una comedia de Aristófanes, se evidencian los horrores de la guerra y la forma de poner fin a la misma, de manera cómica.

El teatro ha sido usado para manipular en favor de regímenes absolutistas o para evangelizar y aprender una lengua. Cutillas (2005) expone la relación que este ha tenido en la educación, señala que, por ejemplo, Rousseau le daba un lugar preeminente en lo que él llamaba "pedagogía del interés". Por pedagogos, como Decroly o dÁlembert, el teatro ha sido valorado como "una institución moral y educadora que debe formar al pueblo y a la humanidad" (Cutillas, 2005) mientras que, dentro de la pedagogía activa, Dewey alude al teatro como una forma de "aprender viviendo". Y desde la base fundamental del proceso de enseñanza, Freinet propone actividades teatrales sobre su convicción de la capacidad fundamental de los niños, de expresarse libremente (Cutillas, 2005).

Esta capacidad, en efecto, ha sido desestimada por las instituciones educativas puesto que, tanto los sueños y propósitos de los estudiantes, como sus problemáticas más comunes: falta de convivencia, pérdida de valores, desinterés en el estudio y conflictos de grupo, entre otros, todavía son abordados desde la educación tradicional, de manera unidireccional e inflexible, sin estrategias que los afronten a partir de sus causas.

Por otro lado, sin ir lejos de dichas problemáticas, Colombia tiene en su historia reciente más de cinco décadas de violencia, arraigada en el abandono de las tierras de los más vulnerables; en el abuso de poder y el clientelismo político; en el desempleo, el narcotráfico, el sicariato, la pérdida de valores, y la indiferencia, entre otros. Una realidad que no excluye a la escuela. De tal manera se hace necesario instaurar una "cultura de paz", la cual, parafraseando a Fisas (2011) responde a una "tarea educativa" alrededor de los problemas de violencia y de la promoción de una ética consciente y participativa que lleva a las personas a asumir los conflictos de una manera distinta. Obviamente, en esta tarea, es necesario que se planteen iniciativas que ayuden a fomentar la cultura de paz, siendo ello, tarea de todos. De los medios, de los políticos, de las empresas, de las organizaciones gubernamentales y no gubernamentales, sobre todo, de la escuela.

Por otra parte, Delors (1996, en Fisas, 2011, p.1) plantea que el comportamiento puede ser modificado 
por el aprendizaje y plantea cuatro ejes en la educación para la paz: (a) aprender a conocer, relacionado con los instrumentos de la comprensión, (b) aprender a hacer, concerniente a la capacidad para actuar sobre determinado medio, (c) aprender a vivir juntos, coherente con la posibilidad de participar y cooperar en comunidad, y (d) aprender a ser, relacionado con la trascendencia. Desde aquí, la educación hacia la paz ha de formar no solo para el disentimiento o la indignación, sino también para la crítica y la reflexión de los valores.

En este sentido, el teatro es una alternativa que no debe subestimarse, ya que, además de poseer la representación; es una opción lúdica y eficaz para la educación de valores. Corredor (2015) quien desarrolló un proyecto teatral en su escuela, afirma que el valor de la representación consiste en el placer que se encuentra en la experimentación escénica de resignificar las situaciones de la vida cotidiana, como lo es la convivencia entre los hombres.

Durante las experiencias teatrales con los estudiantes, Corredor (2015) observó el reflejo de prácticas violentas en su cotidianidad tales como el uso de palabras soeces, intimidación, negación del otro, burla frente a la diferencia, imposición a la fuerza, autoagresión; sin embargo, gracias a las prácticas teatrales, los estudiantes registraron nuevos conocimientos acerca de sí mismos, descubrieron sus potencialidades y talentos en el canto y la danza, y mejoraron la integración entre los estudiantes, optimizando, igualmente, el sentido de la escucha y la apreciación de los aportes ajenos, tanto como el valor que hay en la diferencia.

Por otra parte Nuñez y Navarro (2007) afirman que gracias a las oportunidades de interacción del teatro, se ayuda a desarrollar la comprensión sobre las relaciones con los otros, enriqueciendo las capacidades sociales de cada uno, necesarias dentro de la formación integral de toda persona.

Según Nuñez y Navarro (2007) el teatro es una vía eficiente para la educación en resolución de conflictos, ya que, por medio del juego de roles inherente al drama, el estudiante se encuentra ante diversos escenarios, contradictorios o conflictivos; sobre los cuales, necesita elegir la mejor alternativa. Así, afirman Nuñez y Navarro (2007), "por medio de la dramatización, el estudiante explora conscientemente estados de ánimo y sentimientos."(p. 16), siendo la dramatización, un espacio ideal para el trabajo de la educación emocional y de la inteligencia interpersonal. Esto sería construir cultura de paz, ya que en consenso con lo que dice Fisas (2011), se brinda al individuo las herramientas necesarias para que pueda asumir la autonomía, la libertad y la capacidad de toma de decisiones, con la debida reflexión alrededor de sus actos y de su responsabilidad individual.

En este sentido, el teatro como alternativa de la educación para la paz, pone al estudiante en el escenario de la cotidianidad, bajo un conflicto que buscaría afrontar, reconociendo los intereses del otro, generando empatías, comprendiendo las emociones de los demás y ubicándose en su lugar.

Así, Nuñez y Navarro (2007) reiteran que hay temas transversales que se pueden enseñar en relación con el teatro, entre los cuales, están la educación para la convivencia; la producción colectiva para fomentar el compañerismo y la producción sin competitividad; la educación no sexista, dirigida a evitar la discriminación, y la educación para la solidaridad, puesto que mediante el arte dramático el estudiante aprenderá a descubrir los problemas de su comunidad, despertando en él una sensibilidad social:

... la dramatización como campo de acción es una herramienta de gran eficacia para que los niños y las niñas interioricen actitudes como el diálogo, la tolerancia, la reconciliación, la comprensión y la cooperación, valores necesarios para promover una cultura de paz (p.25).

Con lo anterior, Nuñez y Navarro (2007) abren camino a la pregunta de la incidencia del teatro como un medio para fomentar la cultura de paz en las aulas de las instituciones educativas:

Frente al egoísmo, la competitividad, la superficialidad-frivolidad y el individualismo que imperan en nuestra sociedad, y a favor de una educación que transmita valores de justicia, igualdad, fraternidad y dignidad humana, urge la necesidad de que nuestras escuelas eduquen para la paz, el perdón, la convivencia y el diálogo. En este sentido, es imperiosa una educación en actitudes y habilidades de colaboración que promueva comportamientos de construcción social, de democracia real, que favorecen además el desarrollo integral: cognitivo, volitivo, afectivo, psicosocial del alumnado... La dramatización es un instrumento idóneo para desarrollar esas habilidades interpersonales, que a su vez contribuyen a mejorar las habilidades intelectuales y académicas (p. 25).

El teatro entonces podría ser un medio para fomentar la cultura de paz en el aula porque, como afirman Nuñez y Navarro (2007), "se nos presenta en la escuela como una herramienta educativa para el desarrollo personal y social" (p. 24). Por medio suyo se pueden trabajar en la escuela, las llamadas habilidades sociales, potenciando aspectos básicos de las relaciones interpersonales, como pueden ser la escucha y la aceptación del otro, tal como lo ratifica en párrafos anteriores Corredor. El teatro en la escuela brinda enormes posibilidades para formar en la paz y en la convivencia, por medio de un aprendizaje vivencial.

Ahora bien, Tuvilla (2006) afirma que la educación es importante para la cultura de paz debido a que es, a través de ella, que se pueden superar prejuicios y estereotipos que excluyen y separan a unos de otros. Así mismo, se desarrollan habilidades para comunicarse libremente; se 
fomenta el respeto por los derechos humanos y se aprenden estrategias para resolver conflictos pacíficamente. El teatro es, precisamente, una estrategia que permite desarrollar estas habilidades y construir valores mínimos como respetar la vida, aprender a vivir juntos y aprender a ser, Tuvilla (2006).

De tal suerte, todo proyecto educativo centrado en "saber convivir juntos" debe ir ligado a valores como la solidaridad y el respeto, para lo cual se necesita crear espacios que faciliten la autonomía y la creación de ideas. Significa fomentar nuevas formas de relacionamiento, a partir de espacios de confianza, que hagan posible la resolución pacífica y creativa de conflictos. Los centros educativos serían lugares tan justos como seguros y el teatro, un espacio que brinda una certeza de naturalidad, de protección invulnerable sobre la creación de signos, de participación, de expresión y de comunicación asertiva, teniendo como resultado la mejora de la convivencia y, por ende, un acercamiento a una cultura de paz.

Por su parte, la Organización de las Naciones Unidas para la Educación, la Ciencia y la Cultura. (1999) reconoce que la paz no significa ausencia de conflictos, sino un proceso que involucra dinámicas de participación y diálogo capaces de mediar y solucionar problemas en virtud de la comprensión de los mismos y de la cooperación mutua.

Por ello es que el teatro en la escuela se plantea más que como una dinámica, como una estrategia para fomentar la paz, la mediación y la reflexión, alrededor de la comprensión de conflictos. Así, para promover una cultura de paz por medio de la educación, los agentes educativos, según Programa de la Organización de las Naciones Unidas para la Educación, la Ciencia y la Cultura. (1999) deben, entre otros aspectos:

(a) Velar porque los niños, desde la primera infancia, reciban instrucción sobre valores, actitudes, comportamientos y estilos de vida que les permitan resolver conflictos por medios pacíficos y en un espíritu de respeto por la dignidad humana y de tolerancia y no discriminación; b) Hacer que los niños participen en actividades en que se les inculquen los valores y los objetivos de una cultura de paz (1999, p. 6).

Dichos literales, ratifican la importancia del teatro, no solo como actividad, sino como proceso de vida, de espacio lúdico y creativo, de valores, actitudes y comportamientos que apuntan a la dignificación del ser humano, a la práctica de la tolerancia y de la solidaridad como parte de la inclusión y del respeto hacia ambos géneros, como aplicación del diálogo y el consenso para la resolución de conflictos, elementos éstos, vitales para el fomento de la cultura de paz.

Por otra parte, según afirma Velandia (2015), la calidad de la relación interpersonal tanto laboral como cotidiana, depende de la fluidez y riqueza de la comunicación. Para ello, en la sociedad existen diversos escenarios donde una persona puede interactuar con sus iguales, de ahí que su expresión comunicativa pueda ser formal o informal, participativa o discreta, puesta en acción desde los primeros años de vida.

En este sentido, el teatro, como actividad de contacto permitiría al niño o al joven, integrarse en una sociedad, muchas veces difícil de llevar (por cuanto difiere de los parámetros de vida que lo secundan) y hacer su respectivo aporte, a partir de la forma de ver y percibir el mundo que le rodea. Lo anterior permite que el ser humano tenga una consecución de metas cuya energía se mueve de forma individual y grupal (Velandia, 2009 p. 143).

Esta energía, sobre una actividad de contacto, podría constituirse en el teatro, porque, como lo afirma Boal (2002) "no podemos vivir aislados, encerrados en nosotros mismos. Aprendemos enormemente cuando admitimos nuestra propia otredad: el otro también ama y odia, tiene miedo y es valiente [...] precisamente por eso podemos aprender de los demás: somos distintos siendo iguales" (p.10). En consecuencia, son muchas las posibilidades comunicativas y de interacción social que ofrece la actividad del arte dramático ya que, en palabras de Velandia, permite reorientar la comunicación cuando se hace rígida, nociva, parca o agresiva, siendo esta, la principal herramienta para lograr relaciones auténticas de común-unión (2015, p. 20).

\section{El teatro: alternativa de un nuevo entorno de aprendizaje}

Cacopardo (2011) explica que la violencia que hoy se vive en las aulas es producto de un dispositivo pedagógico moderno, agotado e ineficaz. La escuela, en lugar de hacer pedagogía, hace asistencialismo, no crea subjetividades, y desde aquí, la forma de educar a una persona en la escuela tradicional ha estallado, hay desacople entre las representaciones viejas y las situaciones actuales.

Contrario de lo que se pueda pensar, el enemigo de la educación actual no es la desactualización de los maestros, ni mucho menos de los estudiantes, sino como lo explica Cacopardo (2011), es la idea de lo definitivo, de la competición, la desarticulación (de enfoques y contenidos) y la egolatría. Por eso, urge contar con pedagogías alternativas que le inyecten sangre nueva a las aulas, de modo que la apertura y flexibilidad de pensamiento, circulen por todo el sistema educativo, permeando viejas formas de aprendizaje: efectivas, punitivas, sumativas y unidireccionales, con otras opciones de interacción, más colaborativas y constitutivas en lo social, lo individual y lo institucional. Permear de vida y movimiento nuevos caminos de conocimiento y de aprehensión de la realidad.

Una alternativa pedagógica como el teatro se puede convertir en lo que Robinson y Aronica (2015) llaman, "una experiencia de aprendizaje distinta" (p. 63), que puede innovar concepciones de enseñanza y cambiar 
metodologías para formar sujetos activos, participativos y creativos, siendo estos, protagonistas de sus propios aprendizajes. Tal como lo expresan Assaél, Scherping y Pavez (2011), fundamentalmente, para posibilitar la construcción de una escuela diferente, sin autoritarismos, o formas veladas de discriminación, competencia y desvalorización del otro:

Los docentes tenemos la responsabilidad de construir una propuesta educativa verdaderamente democrática, pero para lograrlo es necesario construir espacios dentro de la escuela donde se reflexione y se evalúe la conducta y la labor de docentes, estudiantes y en general de toda la comunidad (Assaél, Scherping y Pavez 2011, p.16).

Sumado a lo anterior, Freire (2005) defiende una práctica educativa problematizadora y reflexiva, donde los estudiantes desarrollen su poder de captación y comprensión del mundo, pues la realidad no es estática sino que está en constante transformación.

Al respecto, Núñez y Navarro (2007) plantean que el teatro está en el hombre y para el hombre; por lo tanto, es válido para todas las etapas de su desarrollo, independientemente del lugar que ocupe o del momento sociopolítico que lo circunde, porque permite un aprendizaje vivencial y un espacio que hace sentir seguro a quien lo práctica. Premisa que la Organización de las Naciones Unidas para la Educación, la Ciencia y la Cultura Unesco en su documento Replantear la educación: ¿hacia un bien común mundial? ratifica:

El mundo está cambiando: la educación debe cambiar también. Las sociedades de todo el planeta experimentan profundas transformaciones y ello exige nuevas formas de educación que fomenten las competencias que las sociedades y las economías necesitan hoy día y mañana. Esto significa ir más allá de la alfabetización y la adquisición de competencias aritméticas básicas y centrarse en los entornos de aprendizaje y en nuevos enfoques del aprendizaje que propicien una mayor justicia, la equidad social y la solidaridad mundial (UNESCO, 2015, p. 4).

De tal modo, la Unesco y Freire ante el cuestionamiento "qué enseñar", permiten trazar un camino capaz de dar respuesta a lo que igualmente este artículo se ha planteado: ¿por qué el teatro podría ser un medio para fomentar la cultura de paz en las aulas? Fácilmente se podría argumentar que es porque anima esas competencias y esos nuevos enfoques de aprendizaje centrados en la solidaridad y en la justicia social que la escuela, hoy en día, necesita.

Pero Motos, pedagogo, investigador y conocedor de las facultades del arte dramático en la escuela, responde mucho mejor a dicho cuestionamiento, elevándolo incluso a la médula de la institucionalidad educativa: ¿por qué ha de estar el teatro en el currículo? Motos (2009) piensa el teatro, como instrumento, integral y pedagógico puesto que "el individuo no sólo aprende usando la razón, sino también la intuición, las sensaciones, las emociones, los sentimientos" (p. 2). Estos pensamientos y sentimientos se funden en la acción, en otras palabras, en el teatro. De esta manera, el autor destaca el uso de la dramática en el ámbito pedagógico como una alternativa eficiente, en la búsqueda de nuevos ambientes de aprendizaje reconociéndole facultades importantes; al respecto Motos (2009) afirma que, en primer lugar, el teatro permite que el estudiante pueda implicarse tanto cinética como emocionalmente, aprendiendo más profunda y significativamente. En este sentido Motos (2009) argumenta lo siguiente:

Las técnicas dramáticas producen una respuesta total, un conjunto de respuestas verbales y no verbales ante un estímulo o un grupo de estímulos, por lo que proporcionan la oportunidad para realizar actividades auditivas, visuales, motrices y verbales, posibilitando que el sujeto del aprendizaje tenga experiencias simultáneas en todos los planos de su persona y no limitando el aprendizaje a una mera experiencia intelectual (p. 8).

En segundo lugar, el teatro promueve una mayor comprensión de los textos, pues el estudiante se mete dentro del relato e interactúa con conceptos, personajes e ideas. Además, contribuye en gran manera a la enseñanza del lenguaje y el desarrollo del vocabulario.

En el montaje de una obra teatral, el estudiante es atraído desde el momento inicial en el cual se define el argumento, los personajes, las escenas; existen varias técnicas para la escritura de guiones creativos los cuales son muy útiles para fomentar la escritura y la imaginación dentro de la escuela. En tercer lugar, por medio del teatro se puede desarrollar el pensamiento crítico, tan olvidado en las escuelas, ya que a través de las obras teatrales se pueden hacer reflexiones acerca de temas de actualidad, injusticias, asuntos políticos, históricos, culturales, morales, entre otros. En cuarto lugar, el teatro mejora las competencias ciudadanas, ya que por medio de él se fortalece el trabajo cooperativo, pues en el montaje de una obra los estudiantes deben hacer acuerdos, distribuirse labores y personajes, hacer ensayos juntos y en general hacer sinergias para lograr el éxito de la obra. En quinto lugar se puede decir que el teatro proporciona al estudiante sentido de propiedad sobre su aprendizaje, el profesorado deja de ser el protagonista y permite que los estudiantes se conviertan en el eje central. Este aspecto es crucial ya que uno de los problemas de la educación ha sido siempre la gran dependencia en el profesor y la subvaloración o relegación del estudiante a un mero ser pasivo y receptor de conocimientos.

Por medio del teatro, el estudiante crea, inventa, plasma sus experiencias, busca cómo ponerlas en escena, se emociona, busca alianzas, toma notas, organiza, 
construye y ve al maestro como un guía y un facilitador de su proceso creador. Por último, el teatro, como un lenguaje total, trabaja con la interrelación de las artes: literatura, música, pintura, la danza, el canto. En el montaje de una obra teatral se mezclan tareas de varias artes, lo cual hace que todos los estudiantes puedan participar de una u otra manera. En una obra teatral, hay que bailar, se necesita el que maneje la música, el que diseñe la escenografía, hay que pintar, manejar las luces, ayudar a organizar, filmar las experiencias, etc.

En este sentido, a modo de "lenguaje total", el teatro en el aula se erige como una estrategia fundamental no solo para el fomento de las competencias lingüísticas, artísticas y de comunicación de los estudiantes, o para la creación de textos, el estímulo del pensamiento crítico y desarrollo de su proceso cognitivo, sino también, para la comprensión y reinvención de dichas competencias aplicadas en la realidad que le circunda, es decir, en la ciudad y en las calles; en el aula o en la familia: "la cualidad de un artista de verdad es la de inventar sus propias obras de arte a partir de una reinterpretación de la realidad, la cotidianidad y los conflictos en ellas presentes" (García, 2002).

Ahora bien, ¿por qué el teatro? Vigotsky, (2003, p. 85) en su libro La imaginación y el arte en la infancia, más exactamente en el capítulo siete, denominado "El arte del teatro en la edad escolar", argumenta acerca de la importancia de la dramatización en los niños.

Explica Vigotsky (2003, p. 86) que las imágenes creadas por elementos reales, tomados del contexto, se encarnan de alguna manera y se realizan de nuevo en la vida real, aunque de un modo propio, y con ayuda de la imaginación encuentran su realización más plena. Esto es verdad y se puede confirmar recordando un poco la niñez, ¿quién cuando pequeño no jugaba a ser un auto veloz imitando los sonidos del automóvil, corriendo de aquí para allá, dramatizando su representación, acelerando, rugiendo, experimentando sobre todo una enorme satisfacción?

Otra causa que explica la fascinación de los niños por el teatro es su vinculación con los juegos (Vigotski, 2003, p. 87); el juego está muy ligado al teatro, y el teatro al juego, ambos combinan creación, además, dentro del teatro se encierran otras tipologías artísticas, pintura, plástica, fotografía, maquillaje, literatura, etc.

Aquí reside según Vigotsky (2003, p. 87) el verdadero valor de la representación teatral que pueden hacer los niños, como fuente de inspiración y de material para los más diversos aspectos del arte, ya que el montaje de una obra teatral permite que los niños realicen una serie de actividades alrededor de ella:

La preparación del decorado, vestuario y demás, excita la imaginación y la creación técnica de los propios niños. Los niños dibujan, modelan, recortan, cosen y todo ello adquiere sentido y fin como parte de un conjunto, de un sentido que les interesa. Por último, el propio juego, consistente en la representación por los actores, culmina todo este trabajo dándole su expresión total y definitiva (Vigotski, 2003, p. 87).

Pero el teatro no consiste en actuar por actuar, sino que tiene siempre un objetivo determinado, por ejemplo, ilustrar uno u otro acontecimiento revolucionario, un hecho político destacado, criticar creativamente el alcoholismo, la desigualdad, la indiferencia, la avaricia, etc. De tal manera, el docente puede sugerir un tema, la representación de un valor, de un dilema filosófico o moral, de un problema ambiental, un hecho histórico, un cuento leído en clase, una anécdota del mismo estudiante, etc.

Del mismo modo Cañas (2009) plantea "la expresión dramática como una alternativa liberadora" (p.18) que permite la autoconciencia, la aceptación de la realidad y la afirmación propia de la personalidad del estudiante, siendo esta, la mejor forma para articular el movimiento y la palabra en un conjunto armónico de espontaneidad y creatividad. Así, el teatro, se plantea como una expresión completa basada además, en el juego.

...ese juego que conduzca al niño a considerar la propia expresión, en este aspecto de la dramática infantil, como parte fundamental de su libertad personal, el que le permita ver al mundo tal y como es, y a opinar sobre él sin reparo, el que le capacite para disfrutar con otros niños momentos de libertad compartida, de socializarse al formar parte de una aventura común, de sentirse igual, importante y necesario dentro de la colectividad como grupo homogéneo que trabaja junto, que expresa en común (p. 18).

Y además de ser liberadora, la dramática es una expresión formadora. Cañas (2009) habla del "teatro espejo y el teatro aventura” (p. 19), donde los niños que hacen teatro ven el mundo como una opción para atreverse a alterarlo, a partir de su propia visión de mundo. En ese "espejo de lo cotidiano" (2009, p. 19), los niños recrean el mundo. Ese niño o niña que "lucha por tener su propio yo" encuentra que "el teatro es una aventura, abierta y global, sin límites ni espacios fijos, libre” (2009, p. 20).

El aula, espacio de la cotidianidad del estudiante, y el teatro, el medio o la alternativa pedagógica donde extrapola su visión y sus sentimientos, donde fomenta la cultura de paz y pone en práctica valores como la solidaridad y el respeto a la diferencia, o donde se prepara para la resolución de conflictos de una manera lúdica, debido al trabajo compartido y cooperativo con otros.

A manera de "alternativa liberadora", el teatro en el aula permite la autoconciencia, la aceptación de la realidad y la afirmación de la personalidad como insumos fundamentales para la aplicación de una cultura de paz. Cultura que, como ya se dijo, se construye en la capacidad de vivir juntos, en la resignificación de lo cotidiano, y en la práctica del perdón y del diálogo (Cañas, 2009). 


\section{Metodología}

La investigación que llevó a la consolidación del presente artículo es cualitativa, de tipo descriptivo. Los investigadores actuaron como instrumento de medida, sin reglas de procedimiento, de manera flexible evolutiva y recursiva. El enfoque aplicado fue el hermenéutico, basado en la descripción, interpretación y propuesta final de una alternativa pedagógica: el teatro. A través de la creación de obras teatrales se promovieron en el aula valores, acciones y sentimientos que evidenciaron situaciones y problemáticas cotidianas entre educandos y profesores. El paradigma aplicado fue investigación-acción pedagógica a través de una práctica reflexiva, capaz de buscar cambios en la cotidianidad académica, donde el profesor enseña mientras investiga, buscando la transformación y el mejoramiento de la práctica educativa.

Según Restrepo (2002) la investigación-acción pedagógica conlleva tres fases, las cuales se han aplicado en esta investigación:

- Reflexión sobre un área problemática: el área problemática es la convivencia y la construcción de una cultura de paz en el grado noveno el cual es el que presenta mayor nivel de problemas de convivencia, por lo cual se define que este problema debe tratarse mediante una alternativa pedagógica que fomente la participación, motive la interacción y la reflexión acerca de los valores pero de una manera vivencial, escogiéndose así el teatro, como instrumento dentro del aula para fomentar esta cultura de paz; igualmente se realizan cuestionarios donde se evidencian los principales problemas de convivencia, así como los principales valores que se van a trabajar, también se hace una encuesta sobre gustos teatrales.

- Planeación y ejecución de acciones alternativas para mejorar la situación problemática: en esta etapa se plantearon dinámicas, talleres, juegos dramáticos, improvisaciones; asimismo, se diseñó y puso en marcha el blog teatro para la paz, en el cual mediante el teatro foro se fomentó la cultura de paz de modo virtual.

- Evaluación de resultados; durante esta y todas las fases se llevó a cabo una reflexión del proceso día a día, la cual se consignó de forma escrita mediante un diario de campo.

Teniendo en cuenta lo anterior, se ha buscado transformar la teoría en virtud de una investigación interactiva, esto es, una investigación centrada en la práctica, puesto que es en el aula, en las dinámicas con los estudiantes y/o en la representación viva con ellos de la realidad, donde docentes y educandos se involucran, aprehenden nuevas experiencias, desaprenden comportamientos, construyen, inventan, crean y recrean transformando sobre el camino del aprendizaje.
De igual manera, se ha planteado ante todo una transformación dentro de la población escogida, el empoderamiento por parte de ellos hacia la propuesta teatral y el desarrollo de pensamiento crítico ante conflictos y situaciones de su entorno.

Se consideró así mismo, una población de diecinueve estudiantes de noveno grado de Institución Educativa Rural Departamental Andes, San Bernardo, Cundinamarca, área dominada por las FARC-EP entre los años 1993 y 2009. Para el diagnóstico se implementaron los siguientes instrumentos: dos cuestionarios a estudiantes, uno sobre el teatro y su pertinencia en la escuela como proyecto pedagógico alternativo para fomentar la cultura de paz, y otro de quince preguntas, relacionado con la cultura de paz, los valores citados y a la resolución de conflictos; igualmente, se llevaron a cabo dos entrevistas, aplicadas a los directivos de la institución educativa donde se desarrolló la investigación.

\section{Resultados de los instrumentos de diagnóstico}

A continuación se presenta un análisis de los resultados más representativos de cada tipo de instrumento aplicado

Cuestionario a estudiantes mediante escala Likert realizado para diagnosticar elementos de la cultura de paz como el grado de solidaridad, el respeto a la diferencia y la actitud ante los conflictos.

Con esta pregunta se pudo evidenciar en la Figura 1 cómo el $37 \%$ de los estudiantes casi nunca evita responder a una ofensa cuando son ofendidos; es decir, que reaccionan de una u otra manera ante una ofensa, pero nunca se quedan callados. Además, este es un índice muy bajo que indica que se deben buscar alternativas lúdicas y pedagógicas para que los estudiantes aprendan a responder ante una ofensa de una manera asertiva y no violenta.

\section{¿Evito responder a una ofensa cuando soy ofendido?}

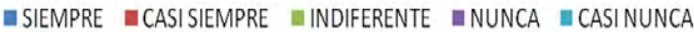

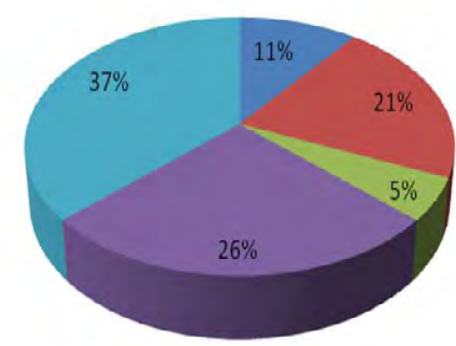

Figura 1. Actitud frente a la ofensa

Fuente: elaboración propia. 
En la Figura 2 se observa que un 32\% casi nunca evita agredir físicamente a alguien si es agredido, en tanto un $31 \%$ lo hace casi siempre, reflejando una actidud opuesta en la misma proporción. Lo anterior indicaría que cerca de la mitad de la población reconoce que asume comportamientos agresivos para defenders; esto corrobora la necesidad de implementar alternativas pedagógicas lúdicas como el teatro en la escuela, con el fin de brindar espacios de reflexión ante la agresión física y el uso de la violencia en general.

\section{¿Evito agredir físicamente si alguien me agrede?}

\section{$\because$ SIEMPRE $\square$ CASISIEMPRE $=$ INDIFERENTE $\backsim$ NUNCA $=$ CASINUNCA}

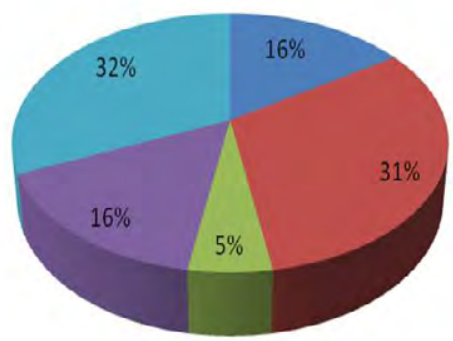

Figura 2. Actitud frente a la agresión

Fuente: elaboración propia.

Un 83\% de estudiantes (Figura 3), casi siempre o siempre acuden al diálogo para solucionar problemas; este porcentaje indica la importancia de fomentar espacios de diálogo y el teatro es un gran instrumento para ello, pues por medio de la dialogicidad que lo caracteriza, se puede reflexionar verbalmente sobre problemas y conflictos, poniéndolos en escena; es decir, convirtiéndolos en diálogo.
En cuanto al cuestionario diseñado para diagnosticar la aceptación del teatro por parte de los estudiantes algunos de los resulados fueron:

La Figura 4 evidencia que un $89 \%$ de los encuestados manifiesta su deseo de hacer teatro y solo un $11 \%$ expresó lo contrario; quiere decir, que la expectativa sobre el arte teatral es muy alta.

\section{¿Te gustaría hacer teatro?}

$$
\because \mathrm{SI}=\mathrm{NO}
$$

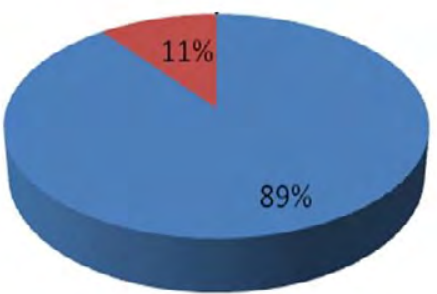

Figura 4. Gusto por el teatro

Fuente: elaboración propia.

Existe un $100 \%$ de aceptación de los jóvenes sobre la necesidad de abrir espacios para realizar obras de teatro en el colegio (Figura 5). Entre las razones expresadas por los estudiantes se manifestó que el teatro es un espacio para compartir con los compañeros; además de ser una buena alternativa para ganar confianza en sí mismos.

\section{¿Consideras que deberían abrirse espacios para realizar obras de teatro en el colegio?}

\section{¿Acudo al diálogo para solucionar problemas?}

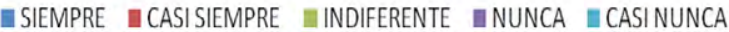

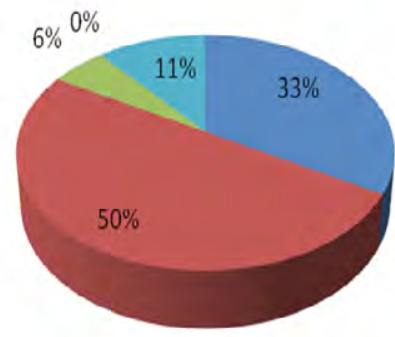

Figura 3. Acercamiento al diálogo

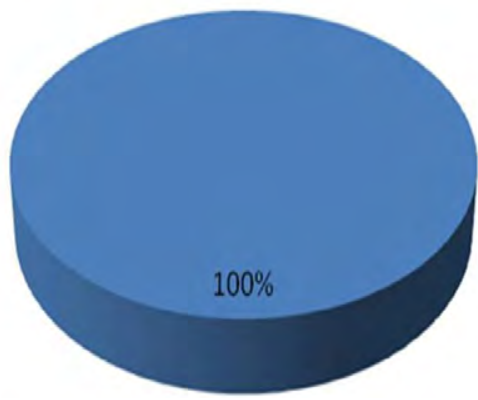

Fuente: elaboración propia.

Figura 5. La posibilidad de abrir espacios para hacer teatro

Fuente: elaboración propia. 
El resultado que refleja la Figura 6, muestra cómo los estudiantes manifiestan su disposición a ser gestores de paz y convivencia a traves del teatro en un $89 \%$, lo cual confirma la la disposición de los estudiantes hacia contemplar el teatro como alternativa para fomentar la cultura de paz.

\section{¿Te gustaría ser gestor de paz y convivencia a través del teatro?}

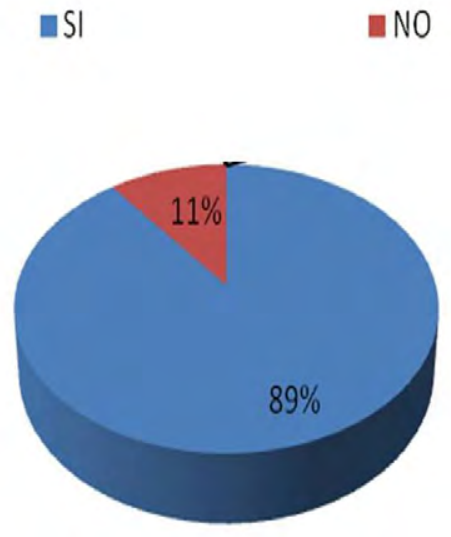

Figura 6. Ser gestor y convivencia de paz a través del teatro

Fuente: elaboración propia.

En cuanto a la entrevista realizada a la rectora y la coordinadora acerca de crear espacios para fomentar la cultura de paz en el colegio y mejorar la convivencia, ambas manifestaron estar totalmente de acuerdo con la creación de espacios argumentando que el teatro es un espacio que permite proyectar al ser humano pacíficamente, la coordinadora opina que es bienvenido porque cree que hace mejorar a los niños y fomenta la cultura de paz.

\section{Propuesta “Teatro para la paz", implementación y resultados}

Teniendo en cuenta los referentes teóricos y los resultados arrojados por los instrumentos aplicados y descritos anteriormente, se diseñó una propuesta denominada "Teatro para la paz"; alternativa pedagógica que toma el teatro como herramienta fundamental para crear espacios de reflexión alrededor de la cultura de paz, la cual está pensada para que a través de la lúdica, el estudiante desarrolle competencias comunicativas que le ayuden a mejorar sus relaciones con los demás, explore y descubra sus talentos y capacidades, construyendo, a su vez, valores como la solidaridad y el respeto por la diferencia.

La propuesta se implementó con un grupo focal de diecinueve estudiantes de grado noveno, para su desarrollo se usaron básicamente tres componentes teatrales: ejercicios dramáticos, improvisaciones, así como ensayos y montajes de obras teatrales; todos centrados en la construcción de valores y el fortalecimiento de la convivencia.
Los ejercicios dramáticos son acciones que se realizan para desarrollar en los estudiantes capacidades de sensibilización, atención, expresión, desinhibición, etc. Por ejemplo, uno de los ejercicios titulado "La silla eléctrica y la silla de plumas" (Figura 7), consistió en hacer un círculo alrededor de una persona y decirle todo lo que molestaba de ella, a la vez lo que más gustaba, permitió comprender muchas situaciones entre los compañeros, así como reconocer los errores individuales y, de esta forma, enmendarlos para mejorar la convivencia.

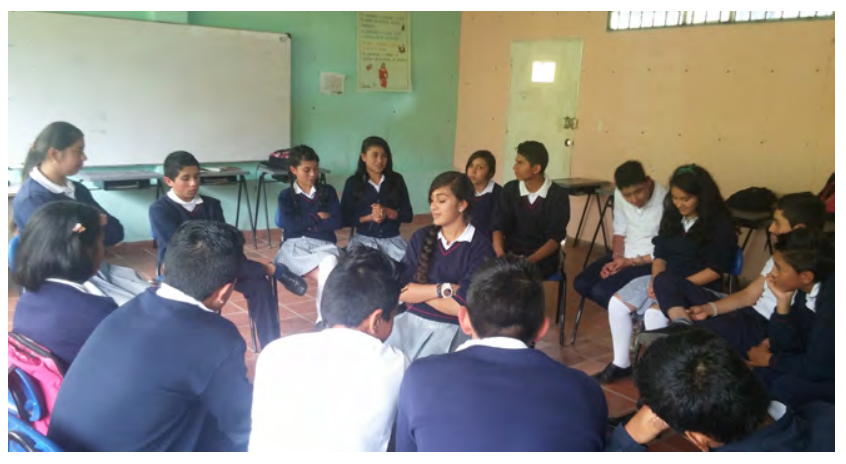

Figura 7. Ejercicio "La silla eléctrica y la silla de plumas"

Fuente: elaboración propia.

Las improvisaciones son creaciones espontáneas de escenas partiendo de un objeto, una canción, una palabra o determinada situación; por ejemplo, con los estudiantes se realizó la improvisación denominada "Televentas" en la cual debían improvisar por grupos un comercial para vender un producto totalmente inútil. El objetivo de este ejercicio de improvisación era fortalecer el trabajo en equipo, la creación colectiva, y persuadir haciendo parecer verdad lo que están vendiendo (Figura 8).

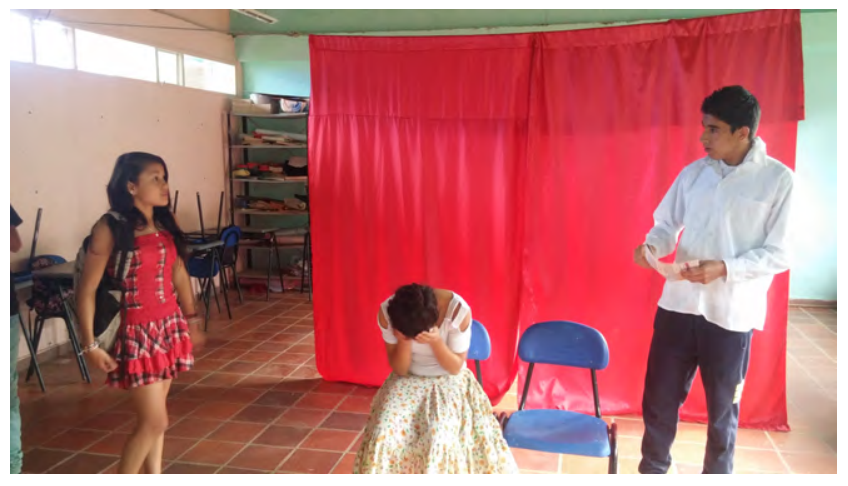

Figura 8. Improvisación, grado noveno

Fuente: elaboración propia.

Vale la pena resaltar que desde el instante en que comenzaron los ejercicios dramáticos y las improvisaciones se empezaron a observar los resultados, teniendo 
presente que estos son espacios de convivencia, donde no solamente se prepara una obra teatral, sino que se comparten momentos de la cotidianidad.

Las obras que posteriormente se montarían son resultado de estas improvisaciones y ejercicios dramáticos, los cuales se alimentan en gran medida de la cotidianidad y contexto de los estudiantes. Por ejemplo la obra "Se nos murió la tristeza", es el resultado de una improvisación acerca de cómo sería el velorio de una emoción como la tristeza (Figura 9).

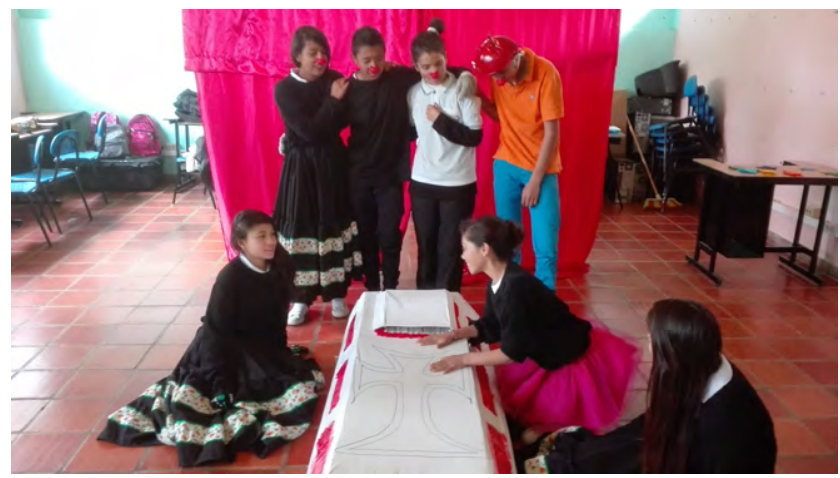

Figura 9. Obra Se nos murió la tristeza. Grado noveno

Fuente: elaboración propia.

El ensayo ya de las obras es un periodo muy importante en el cual los estudiantes deben tener un gran trabajo colaborativo para entenderse entre ellos y limar asperezas; un buen resultado depende de todos en general y de cada uno en particular, allí se deben pulir errores, mejorar los personajes, etc. El ensayo provee una excelente oportunidad para convivir sanamente, disfrutando de la compañía de amigos y compañeros de clase; de hecho, algunos estudiantes manifestaron que, a través de los ensayos, pudieron conocer más a sus compañeros de clase e identificarse con algunas cosas que ignoraban de la vida personal de ellos (Figura 10).

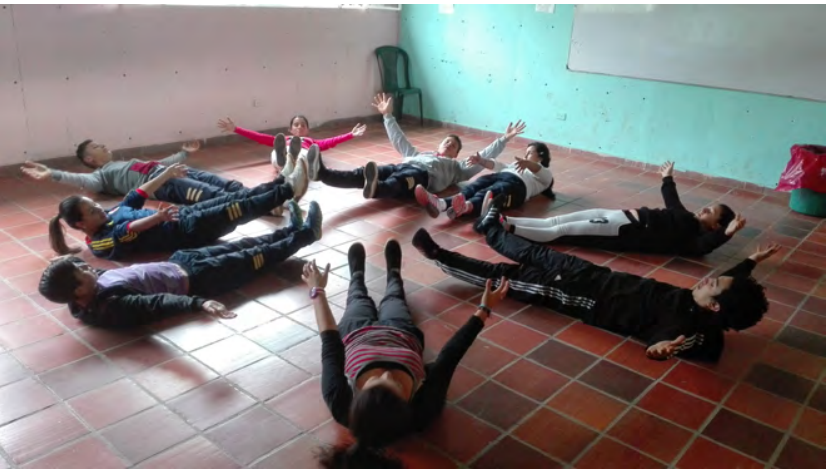

Figura 10. Ensayo

Fuente: elaboración propia
En el montaje de las primeras obras, salieron muchos talentos a la luz, en especial el de un estudiante, quien era subestimado tanto por sus compañeros como por los docentes; sin embargo, poseía una forma muy particular de expresión la cual se convirtió en uno de los pilares del trabajo teatral del grado noveno, sus compañeros disfrutaron con sus intervenciones.

De igual manera sucedió en el montaje de la obra "Gracias por las flores" la cual dejó una reflexión en torno a la necesidad de tomar el juego como un gesto de paz de adultos a niños y una reflexión acerca de la guerra.

Vale la pena resaltar que otros cursos (grado octavo $\mathrm{y}$ once) manifestaron su interés en hacer parte de la propuesta; por tal razón, siendo el teatro un arte incluyente, se abrieron dos espacios para permitir la participación de estos grupos. Así se pudieron montar las obras "Mì querido señor guerra" (Figura 11) y "Dos porciento pa' meter las patas".

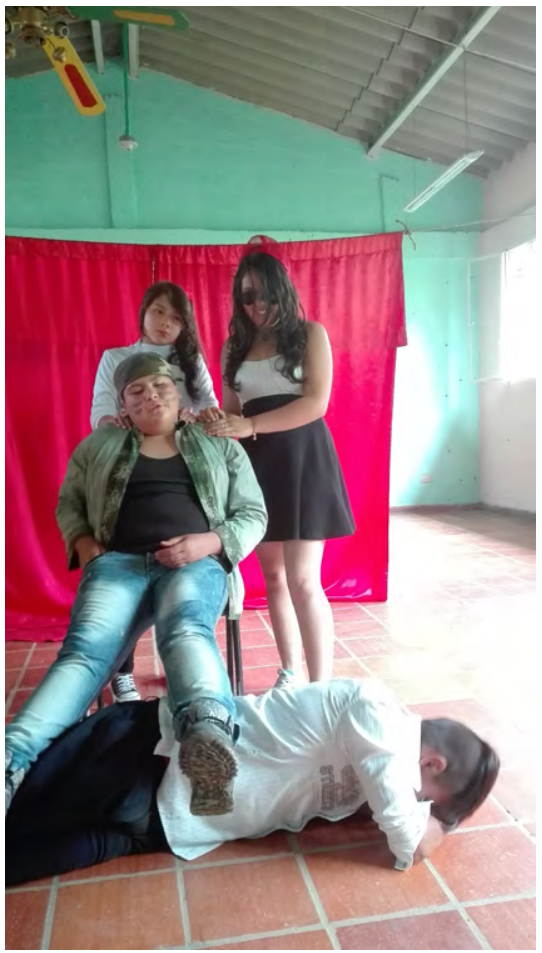

Figura 11. Montaje obra "Mi querido señor guerra", grado octavo

Fuente: elaboración propia.

Ahora bien, para complementar y fortalecer la propuesta se creó el blog "Teatro para la paz" - www.teatroypaz.blogspot.com.co-, en el cual se subieron las obras, previamente filmadas y editadas, para la realización de los teatroforos, con el fin de expandir la participación y la reflexión alrededor de cada una de las obras (Figura 12). 


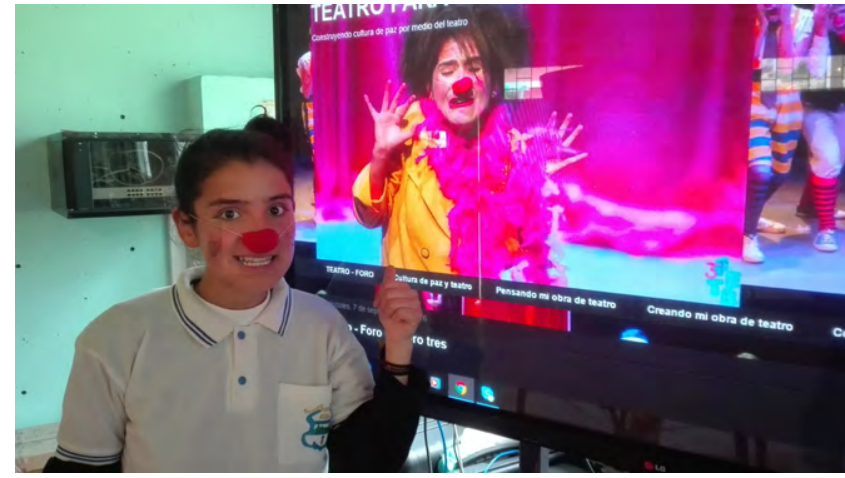

Figura 12. Socialización en la IERD del blog "Teatro para la paz"

Fuente: elaboración propia.

El teatroforo se basa en la representación de una obra teatral con el fin de que los espectadores participen aportando preguntas $\mathrm{u}$ opiniones con respecto a situaciones de la obra y de igual manera planteen soluciones respecto al conflicto representado.

En total se montaron y subieron al blog cinco obras teatrales: "La línea que enlínea la línea", "Quiero ser independiente", "Dos porciento pa' meter las patas", "Mi querido señor guerra" y "Gracias por las flores." De igual manera se han hecho los teatroforos con estudiantes de diferentes instituciones, una de ellas, el colegio Jaime Garzón de la localidad de Sumapaz.

Además de la sección de teatroforos, el blog cuenta con tres secciones: en la sección "Pensando mi obra de teatro" se consigna la parte lógica o cognitiva del teatro, enfocada en las competencias del "saber" es decir, los saberes previos que debe tener el estudiante antes de iniciar a hacer teatro como obras, dramaturgos, principales expresiones dramáticas y elementos de una obra dramática, entre otros.

En la sección "Creando mi obra de teatro" se consigna la parte práctica del teatro, competencias del "hacer", como el montaje de una obra de teatro o la fabricación de elementos escenográficos.

La sección "Conviviendo con mi obra de teatro" centrada en la parte actitudinal y emocional del teatro, es decir todo lo relativo al "ser", como ejercicios dramáticos para fomentar la paz, el cuerpo como instrumento de paz.

De igual manera, hay una sección denominada "Cultura de paz y teatro" donde se habla de la cultura de paz y se explica la relevancia que puede tener el teatro como alternativa pedagógica para ayudar a construirla.

Implementada la propuesta, se diseñaron tres encuestas con el fin de evaluar los resultados, una a los estudiantes con los cuales se desarrolló el proyecto (grupo focal), otra con estudiantes que solo participaron en los teatro foro y una a directivos y docentes de la institución. Dentro de los resultados vale la pena destacar que los estudiantes reconocieron haber aprendido a trabajar en equipo, estrechando lazos de solidaridad dentro y fuera del escenario, mejorando las relaciones de convivencia. De igual manera, manifestaron la valoración por el teatro como una contribución para expresarse en público sin temor. Muchos identificaron la realidad a través de las obras y la esperanza en que los sueños se pueden volver realidad.

Del mismo modo, afirmaron que el teatro se convirtió en un vehículo para superar algunas actitudes que ellos consideraban negativas como la envidia, las divisiones y la apatía a participar en actos culturales; reconocieron en el humor un vínculo propicio para llevar mensajes de paz y de respeto. Muchos de ellos coincidieron en que se habían vuelto más respetuosos en sus relaciones interpersonales y que estaban aprendiendo cosas nuevas y diferentes.

Con respecto a los teatroforos los participantes manifestaron que en efecto las obras representadas los habían hecho reflexionar acerca de valores como la solidaridad y el respeto a la diferencia, además manifestaron su deseo de participar en proyectos de teatro con el fin de ser promotores de paz.

Por otra parte, las directivas de la IERD Andes, afirmaron que el teatro en la escuela sí ha ayudado a fomentar la cultura de paz en los estudiantes de grado noveno porque se evidencia, que han empezado a trabajar en equipo y han mejorado su disposición colaborativa. Según ellas, el teatro recrea situaciones cotidianas donde el estudiante reflexiona sobre la importancia de la convivencia en paz y el respeto. De igual manera, señalaron como observaron, empoderamiento del sentido de pertenencia institucional, mayor tolerancia, empatía, solidaridad y aprovechamiento del tiempo libre en los jóvenes.

Ahora bien, en cuanto al mejoramiento del respeto, la resolución de conflictos, y la solidaridad, los docentes de la de la IERD Andes consideran que el teatro en la escuela como alternativa pedagógica ha permitido que los estudiantes del grado noveno hayan adquirido responsabilidad, empatía, sentido de pertenencia y respeto hacia sus compañeros. También señalaron que, por medio del teatro, los estudiantes aportan de manera positiva en la construcción de la paz y el derecho a una vida digna. Estos valores son expresados en la interpretación de situaciones cotidianas donde se refleja la creatividad de los estudiantes, llegando a toda la comunidad educativa cuando invitan a los espectadores a hacer su propio aporte hacia la paz.

\section{Discusión}

El teatro es una alternativa para fomentar la cultura de paz porque educa para la convivencia y el diálogo y representa una invaluable opción, al articular el arte, el movimiento y la palabra; además, estimula el pensamiento crítico, fundamental para el ejercicio de las competencias comunicativas y ciudadanas, para la reinvención e interpreta- 
ción de sus actos, como parte de su libertad y autonomía.

Los docentes y las instituciones educativas, tienen así, la responsabilidad de coadyuvar con la presentación de un nuevo escenario, verdaderamente democrático, flexible y abierto donde quepa la reflexión y la crítica, tanto como la creatividad, la confianza, la solidaridad, el respeto a la diferencia y el trabajo en equipo, como parte de una cultura de paz. A favor de una educación alternativa que transmita valores de justicia, igualdad, fraternidad y dignidad, frente al egoísmo, la competitividad, la trivialidad y la falta de solidaridad de la sociedad moderna, urge la necesidad de que nuestras escuelas eduquen para la paz, el perdón, la convivencia y el diálogo.

El aula, es el espacio de la cotidianidad del estudiante, y el teatro, el medio o la alternativa pedagógica donde extrapola su visión, sus sentimientos y experiencias. Es el espacio donde se ponen en práctica valores como la solidaridad y el respeto a la diferencia, y donde se permite la reflexión en resolución de conflictos, por el trabajo en equipo y colaborativo con otros.

Lo anterior conduce a manifestar que, en el marco de la paz, la enseñanza cumple una misión importante en la educación: enseñar la diversidad de la especie humana y fomentar la conciencia sobre las semejanzas y la interdependencia de los seres, a partir del descubrimiento de las personas alrededor y de sí mismo. El teatro en la escuela, por ende, tendría la bondad de ayudar al estudiante a conocer las similitudes y de respetar las diferencias con los demás, por cuanto está basado en la interacción y en el descubrimiento de cada ser. En este sentido el teatro como alternativa pedagógica cumple con dos aspectos esenciales que según Tuvilla (2006) y Delors (1996, en Fisas, 2011, p. 1) debe incluir una educación que trabaje por la paz: aprender a ser y aprender a vivir juntos.

Por otra parte, la propuesta "Teatro para la paz" demostró que el teatro como alternativa pedagógica sirve para desarrollar lo que Nuñez y Navarro (2007, p. 24) llaman habilidades sociales, ayudando a mejorar las relaciones interpersonales, la escucha y la aceptación del otro. El teatro como alternativa para una cultura de paz es además una estrategia pedagógica para crear espacios de reflexión alrededor del comportamiento humano, fortaleciendo las capacidades cognitivas, operativas y creativas. Como propuesta lúdica y emancipadora, le devuelve al estudiante el protagonismo y el interés en su proceso de formación, siendo la excusa perfecta para que explore y descubra sus talentos y capacidades y para que desarrolle competencias comunicativas, de lectoescritura y de construcción de valores como la solidaridad y el respeto por la diferencia.

Las TIC, por su parte, complementan la intención pedagógica del teatro, como mediación para la promoción, socialización y difusión de contenidos o valores inherentes a una cultura de paz simulada, vivenciada y representada. En este caso la implementación de teatroforos posibilitó que las obras llegaran a sitios que, por su lejanía, han sido olvidados y donde es difícil encontrar grupos teatrales. En este sentido el uso de las tecnologías de la información y la comunicación TIC se convirtieron en una herramienta esencial para la promoción y difusión de la propuesta que de igual manera, pueda ser implementada en cualquier institución educativa.

En consecuencia, el teatro como alternativa para la cultura de paz, ayuda a producir felicidad y satisfacción en quienes lo realizan, además de constituirse en un puente de reconocimiento, de identificación y de diferenciación frente al otro; en este sentido, el teatro es un medio, puesto al servicio de niños y jóvenes, no un fin. Una herramienta para educar personas, crear conciencia y mover a la reflexión.

\section{Referencias}

Assaél, J., Scherping, G. y Pavez, J. (2011). Rol sindical y docente en la renovación pedagógica. En Naso, Ed., \& I. d. Latina (Ed.). Una pedagogía alternativa en defensa de la escuela pública, 1. (pp.5-24). Nasso: San José. Recuperado de http://www.ei-ie-al.org/publicaciones/modulos1y2_web.pdf

Boal, A. (2002). juegos para actores y no actores. Barcelona: Alba editorial.

Cacopardo, A. (2011). Una pedagogía alternativa en defensa de la escuela pública. En Naso, Ed., \& I. d. Latina (Ed.). Una pedagogía alternativa en defensa de la escuela pública, 1. (pp.5-24). Nasso: San José. Recuperado de http://www.ei-ie-al.org/publicaciones/modulos1y2_web.pdf

Cañas, T. (2009). Didáctica de la expresión dramática, una aproximación a la dinámica teatral en el aula. Barcelona: Octaedro.

Corredor, A. (2015). Hic et nunc: el cuerpo en la educación. Una experiencia de teatro en el aula para el aquí y el ahora. Educación y ciudad, 28, 49-55.

Cutillas, S. (2005). La enseñanza de la dramatización y el teatro: Propuesta didáctica para la enseñanza secundaria. Valencia: Servei de Publicacions.

Fisas, V. (2011). Educar para una cultura de paz. Barcelona: Escola de cultura de Pau.

Freire, P. (2005). Pedagogía del oprimido. Mexico: Grupo Editorial siglo XXl.

Garcia, S. (2002). teoria y practica del teatro vol. Bogota, Colombia: Ediciones teatro la candelaria.

Gual, C. G. (2005). Democracia, teatro y educación en la Atenas clásica (pp. 1-15). Madrid: Universidad Complutense de Madrid. Recuperado de http://antiqua.gipuzkoakultura.net/pdf/gual2.pdf

Motos, T. (2009). El teatro en la educación secundaria: Fundamentos y retos. Revista Creatividad y Sociedad, 14, 2-35. Recuperado de http://centroderecursos.alboan.org/ebooks/0000/0847/5 APY_REE_2.pdf

Nuñez, C., y Navarro, S. (2007). Dramatización y educación: aspectos teóricos. Teor. educ. 19, 225-252. Recuperado de https://gre- 
dos.usal.es/jspui/bitstream/10366/71846/1/Dramatizacion_y_ educacion_aspectos_teori.pdf

Organización de las Naciones Unidas para la Educación, la Ciencia y la Cultura. (1999) Resoluciones Aprobadas por la Asamblea General de las Naciones Unidas. Declaración y Programa de Acción sobre una Cultura de Paz. Recuperado de http://fund-culturadepaz. org/DECLARACIONES\%20RESOLUCIONES/Declaracion\%20 Cdpaz\%20Esp.pdf

Restrepo, B. (2002). Una variante pedagógica de la investigación-acción educativa. OEI-Revista Iberoamericana de Educación. Recuperado de http://rieoei.org/inv_edu12.htm

Robinson, K., y Arónica, L. (2015). Escuelas creativas. Editorial Grijalbo: Colombia
Tuvilla, R. (2006). I Jornadas de Cooperación Educativa con Iberoamérica sobre Educación y Cultura para la Paz.

UNESCO.(2015). Replantearla educación. Ediciones Unesco. Recuperadodehttp://unesdoc.unesco.org/images/0023/002326/232697s. pdf

Velandia, M . (2015). Estrategias comunicativas interpersonales en la práctica docente. Bogotá, D.C.: Universidad Cooperativa de Colombia.

Vigotski, L. (2003). La imaginación y el arte en la infancia 